\title{
Adaptive Educational Systems
}

\author{
Valerie J. Shute, Florida State University, Tallahassee, FL
}

Diego Zapata-Rivera, Educational Testing Service, Princeton, NJ

\begin{abstract}
This paper elaborates on the need for adaptive educational systems, describes an evidence-based, four-process framework for analyzing adaptive educational systems, and reviews several adaptive technologies and types of adaptive learning environments. In addition, interviews with experts in the field inform our discussion on what to adapt, how to adapt, and the future of adaptive educational systems.
\end{abstract}

Keywords: Adaptive educational systems, adaptive technologies, soft technologies, and hard technologies.

\section{INTRODUCTION}

Adaptive educational systems monitor important learner characteristics and make appropriate adjustments to the instructional milieu to support and enhance learning. The goal of adaptive educational systems, in the context of this paper, is to create an instructionally sound and flexible environment that supports learning for students with a range of abilities, disabilities, interests, backgrounds, and other characteristics. The challenge of accomplishing this goal depends largely on accurately identifying characteristics of a particular learner or group of learners - such as type and level of knowledge, skills, personality traits, affective states-and then determining how to leverage the information to improve student learning (Conati, 2002; Park and Lee, 2004; Shute et al., 2000; Snow, 1989, 1994).

We present a general evidence-based framework for analyzing adaptive learning technologies. We then describe experts' thoughts on: (1) the variables to be taken into account when implementing an adaptive learning system (i.e., what to adapt), and (2) the best technologies and methods to accomplish adaptive goals (i.e., how to adapt). We conclude with a summary of key challenges and future applications of adaptive learning technologies. These challenges include: (1) obtaining 
useful and accurate learner information on which to base adaptive decisions, (2) maximizing benefits to the learner while minimizing costs associated with adaptive technologies, (3) addressing issues of learner control and privacy, and (4) figuring out the bandwidth problem, which has to do with the amount of relevant learner data that can be acquired at any time.

\section{Rationale for Adapting Content}

The attractiveness of adaptive technologies derives from the wide range of capabilities that these technologies afford. One capability involves the real-time delivery of assessments and instructional content that adapt to learners' needs and preferences. Other technology interventions include simulations of dynamic events, extra practice opportunities on emergent skills, and alternative multimedia options, particularly those that allow greater access to individuals with disabilities. We now provide evidence that supports the importance of adapting content to students to improve learning. These arguments concern individual and group differences among students.

Differences in Incoming Knowledge, Skills, and Abilities. The first reason for adapting content to the learner has to do with general individual differences in relation to incoming knowledge and skills among students. These differences are real, often large, and powerful; however, our educational system's traditional approach to teaching is not working well in relation to the diverse population of students in U.S. schools today (Shute, 2007). Many have argued that incoming knowledge is the single most important determinant of subsequent learning (Alexander \& Judy, 1988; Glaser, 1984; Tobias, 1994). Thus, it makes sense to assess students' incoming knowledge and skills to provide a sound starting point for teaching. A second reason to adapt content to learners has to do with differences among learners in terms of relevant abilities and disabilities. This addresses issues of equity and accessibility. To illustrate, a student with visual disabilities will have great difficulty acquiring visually presented material, regardless of prior knowledge and skill in the subject area. Student abilities and disabilities can usually be readily identified and content adapted to accommodate the disability or leverage an ability to support learning (Shute et al., 2005).

Differences in Demographic and Sociocultural Variables. Another reason to adapt content to learners relates to demographic and sociocultural differences among students, which can affect learning outcomes and ultimately achievement (Conchas, 2006; Desimone, 1999; Fan \& Chen, 2001). For example, training on a foreign language may contain different content depending on whether the learner is a child or an adult. 
Differences in Affective Variables. In addition to cognitive, physical, and sociocultural differences, students' affective states fluctuate both within and across individuals. Some of these states may influence learning - such as frustration, boredom, motivation, and confidence (Conati, 2002; Craig et al., 2004; D’Mello \& Graesser, Chapter X this volume; Ekman, 2003; Kapoor \& Picard, 2002; Litman \& Forbes-Riley, 2004; Picard, 1997; Qu et al., 2005).

In summary, there are a number of compelling reasons to adapt content to learners. We now provide context and coherence for adaptive technologies by way of a general evidence-based, fourprocess model. This model has been extended from (1) a simpler two-process model that lies at the heart of adaptive technology (diagnosis and prescription), and (2) a process model to support assessment (Mislevy et al., 2003).

\section{Four-Process Adaptive Cycle}

The success of any adaptive technology to promote learning requires accurate diagnosis of learner characteristics (e.g., knowledge, skill, motivation, persistence). The collection of learner information can then be used as the basis for the prescription of optimal content, such as hints, explanations, hypertext links, practice problems, encouragement, metacognitive support, and so forth. Our framework involves a four process cycle connecting the learner to appropriate educational materials and resources (e.g., other learners, learning objects, applications, and pedagogical agents) through the use of a learner $\operatorname{model}^{1}$ (see Figure 1). The components of this four-process cycle include capture, analyze, select, and present.

\footnotetext{
${ }^{1}$ The terms "student model" and "learner model" are used interchangeably in this chapter. They are abbreviated as either SM or LM. Because this paper focuses on the educational functions of adaptive systems, we limit our modeling discussion to the context of students or learners, rather than more broadly defined users.
} 


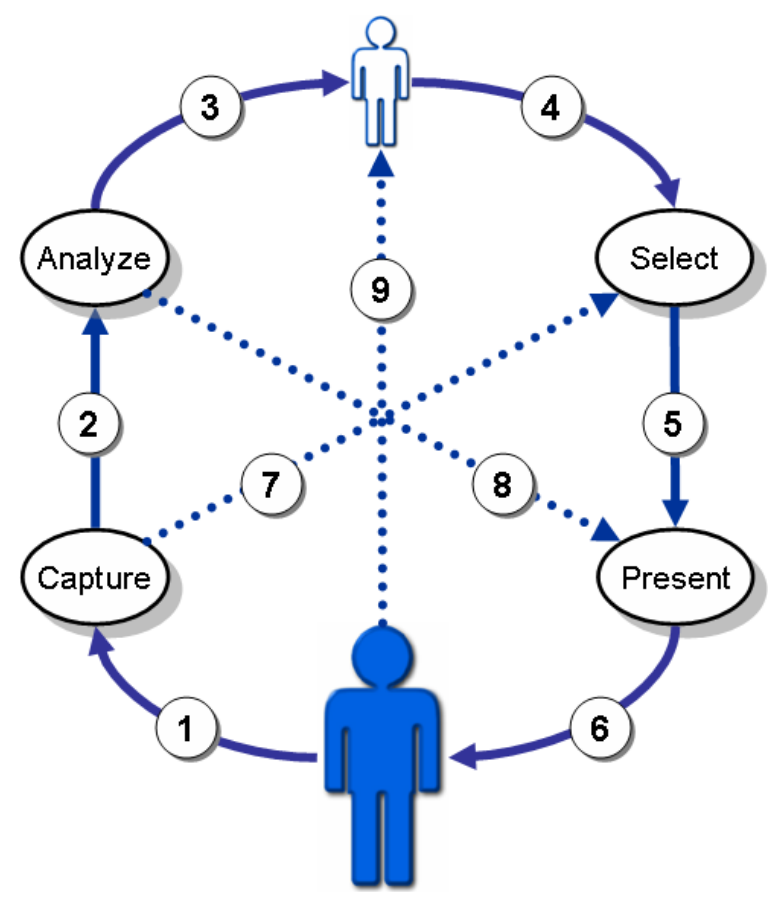

Figure 1. Four-process adaptive cycle. The larger human icon represents the student. The smaller human icon represents the student model.

\section{Capture}

This process entails gathering information about the learner as the learner interacts with the environment (depicted in Figure 1 by the larger human figure). Relevant information can include cognitive data (e.g., solution to a given problem) as well as noncognitive aspects of the learner (e.g., engagement). This information is used to update internal models maintained by the system.

\section{Analyze}

This process requires the creation and maintenance of a model of the learner in relation to the domain, typically representing information in terms of inferences on current states. That is, the computer can infer what the learner knows or can do directly from aspects of the learner's performance in the learning domain (e.g., if the learner solves a relatively difficult problem correctly, the inference is that her knowledge and/or skill related to the topic is likely pretty good, and if she solves another difficult problem correctly, the confidence in the inference that she knows the content well increases). In Figure 1, this is depicted as the smaller human figure, and is often referred to as the student model or the learner model. 


\section{Select}

Information (i.e., content in the broadest sense) is selected for a particular learner according to: (a) her current status as represented in the student model, and (b) the purpose(s) of the system (e.g., next learning object or test item). This process is often required to determine how and when to intervene.

\section{Present}

Based on results from the select process, specific content is presented to the learner. This entails appropriate use of media, devices, and technologies to efficiently convey information to the learner.

This model accommodates alternative types and levels of adaptation. Table 1 describes some of the different possibilities, starting with a completely adaptive cycle and continuing to a nonadaptive presentation.

Table 1. Scenarios represented in the 4-process adaptive cycle

\begin{tabular}{|l|l|}
\hline \multicolumn{1}{|c|}{ Scenario } & \multicolumn{1}{c|}{ Description } \\
\hline $\begin{array}{l}\text { A complete outer cycle, } \\
\text { automated adaptation (1,2,3,4, } \\
5, \text { and } 6)\end{array}$ & $\begin{array}{l}\text { All processes of the cycle are exercised: capturing relevant information, analyzing it, } \\
\text { updating the variables which are modeled in the learner model, selecting appropriate } \\
\text { learning resources and strategies that meet the current needs of the learner, and making } \\
\text { them available to the student in an appropriate manner. This cycle will continue until the } \\
\text { goals of the instructional activity have been met. }\end{array}$ \\
\hline $\begin{array}{l}\text { Automated adaptation with user } \\
\text { input }(1,2,3,4,5,6, \text { and } 9)\end{array}$ & $\begin{array}{l}\text { The learner is allowed to interact with the learner model. The nature of this interaction } \\
\text { and the effects on the learner model can vary (e.g., overwriting the value of a particular } \\
\text { variable). Allowing student input to the model may help reduce the complexity of the } \\
\text { diagnostic and selection processes by decreasing the level of uncertainty inherent in the } \\
\text { processes. It can also benefit the learner by increasing learner awareness and supporting } \\
\text { self-reflection. }\end{array}$ \\
\hline $\begin{array}{l}\text { Diagnosis only (1, 2, and 3) } \\
\text { Short (or temporary) memory } \\
\text { cycle (1, 7, 5, and 6) }\end{array}$ & $\begin{array}{l}\text { The learner is continuously monitored; information gathered is analyzed and used to } \\
\text { update learner profiles, but not to adapt content. This may be seen as analogous to } \\
\text { student assessment. }\end{array}$ \\
\hline $\begin{array}{l}\text { The selection of content and educational resources is done by using the most recent } \\
\text { information gathered from the learner (e.g., current test results and navigation } \\
\text { commands). Adaptation is performed using information gathered from the latest } \\
\text { interaction between learner and the system. }\end{array}$ \\
\hline $\begin{array}{l}\text { A predefined path on the curriculum structure is followed. No learner model is } \\
\text { maintained. This predefined path dictates which educational resources and testing } \\
\text { materials are presented to the learner. }\end{array}$ \\
\hline
\end{tabular}


In general, the architecture of adaptive applications has evolved in a way that reflects the evolution of software systems architecture; for example, it is possible to find stand-alone adaptive applications where the complete adaptive system — including its student model—resides in a single machine. Also, adaptive applications have been implemented using a distributed architecture model. Some examples of distributed applications include: (1) client-server adaptive applications that make use of student modeling servers and shells (Fink \& Kobsa, 2000); (2) distributed agent based platforms (Azambuja et al., 2002; Vassileva et al., 2003); (3) hybrid approaches involving distributed agents and a student modeling server (Brusilovsky et al., 2005; Zapata-Rivera \& Greer, 2004); (4) peer-to-peer architectures (Bretzke \& Vassileva, 2003); and (5) service-oriented architectures (Fröschl, 2005; González et al., 2005; Kabassi \& Virvou, 2003; Trella et al., 2005; Winter et al., 2005).

To illustrate how our four-process adaptive model can accommodate more distributed scenarios, Figure 2 depicts an extended version of our model. Agents (e.g., application, personal, and pedagogical agents) maintain a personal view of the learner using their own representation of the "four-process adaptive cycle" (see Figure 1). Agents share (or negotiate) personal information with other agents in order to accomplish goals on behalf of the learner. A common learner model is maintained in a learner modeling server. 


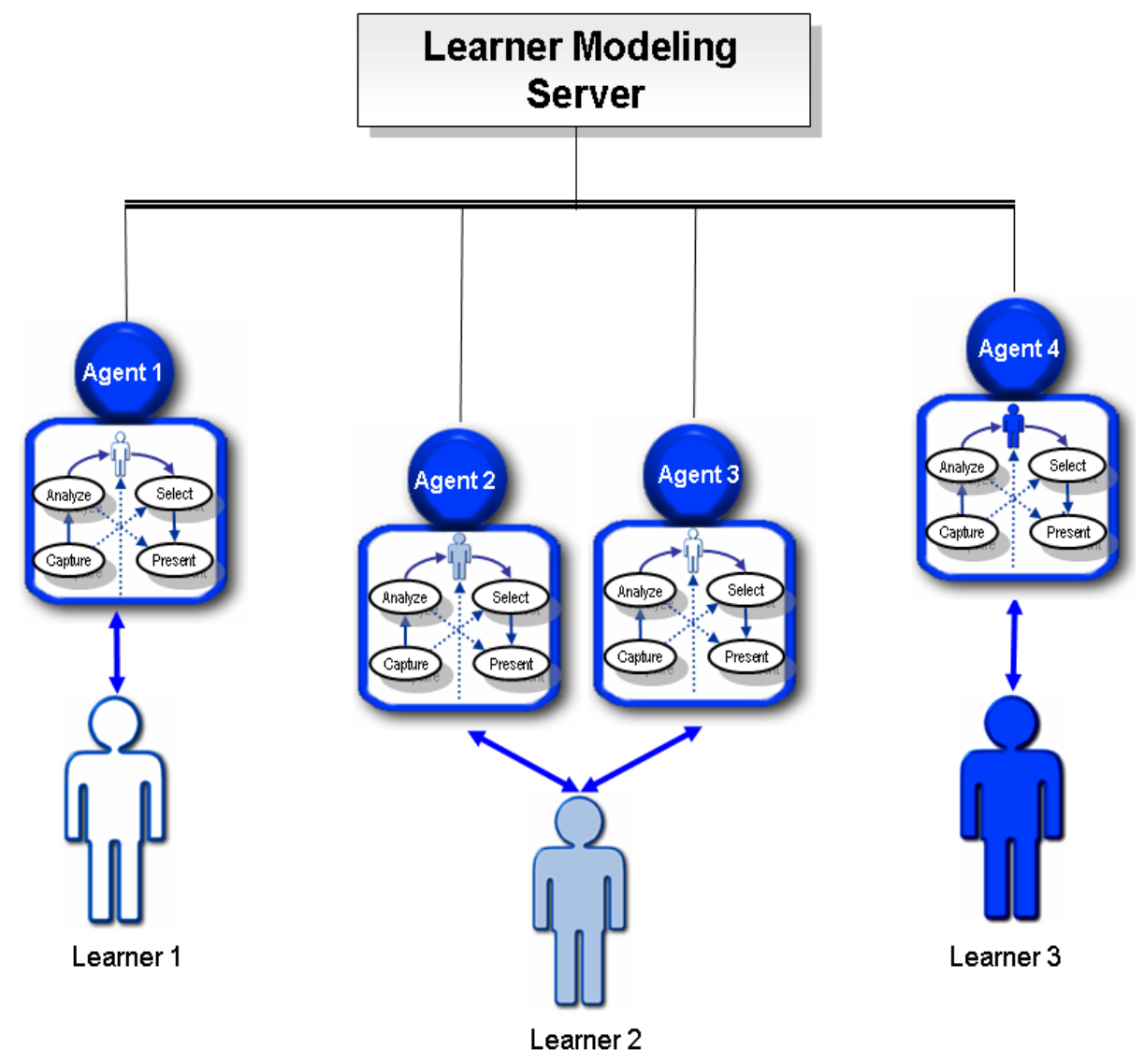

Figure 2. Communication among agents and learners

\section{SUMMARY OF CURRENT ADAPTIVE TECHNOLOGIES}

This section describes adaptive technologies currently in use and relevant to the context of this paper. The technologies have been divided into two main sections: soft and hard technologies. This distinction may be likened to program vs. device, for soft vs. hard technologies respectively, and may be used across the array of processes described in the previous section (i.e., capturing student information, analyzing it, selecting content, and presenting it). The technologies selected for inclusion in this section are those that make use of, to some extent, a learner model in its formulation. Also, this listing is intended to be illustrative and not exhaustive. For a more thorough description of adaptive technologies in the context of e-learning systems, see Fröschl (2005), Kobsa (2006), Jameson (2008), and Buxton (2006), the latter for a directory of sources for input technologies.

Figure 3 provides examples of both soft and hard technologies (in shaded boxes) operating within an adaptive learning environment in relation to our four process adaptive cycle; for example, 
technologies for analyzing and selecting learner model (LM) information include Bayesian networks and machine learning techniques. These technologies are examined in relation to both learner variables (cognitive and noncognitive) and modeling approaches (quantitative and qualitative). Similarly, examples of soft and hard technologies are provided for the processes of capturing and presenting information.

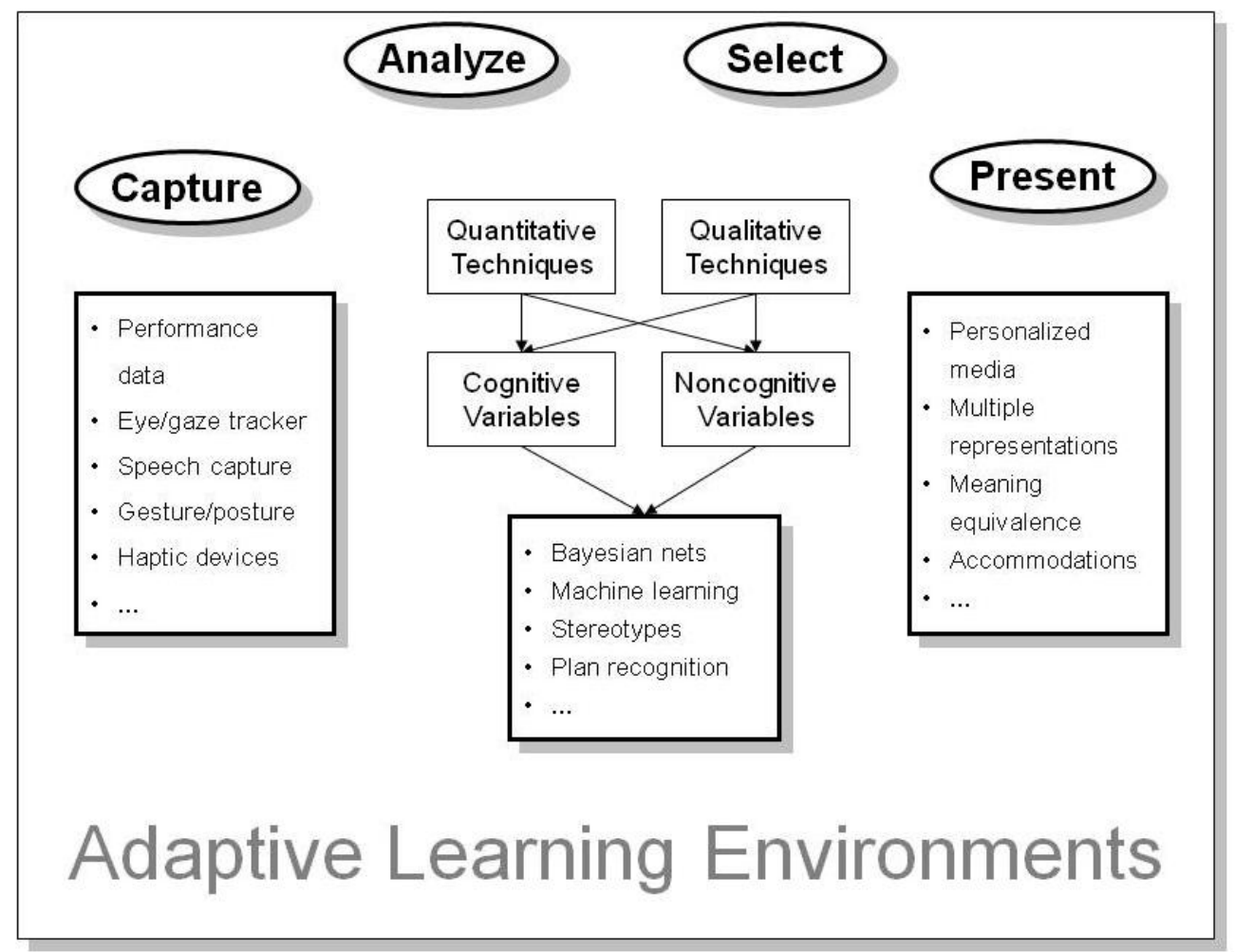

Figure 3. Overview of technologies to support learner modeling

\section{Soft Technologies}

Soft technologies represent programs or approaches that capture, analyze, select, or present information. Their primary goals are to create LMs (diagnostic function) and to utilize information from LMs (prescriptive function).

\section{Quantitative Modeling}

In general, quantitative modeling of learners obtains estimates about the current state of some attribute. This involves models and datasets, as well as typically complex relationships and calculations. To begin modeling, relationships are established and tested, in line with a hypothesis that forms the basis of the model and its test. To quantify the relationships, one can use graphical 
models to create graphs of the relationships and statistical models that will define quantitative equations of expected relationships to model uncertainty (for more, see Jameson, 1995).

\section{Qualitative Modeling}

Qualitative modeling supports learners by constructing conceptual models of systems and their behavior using qualitative formalisms. According to Bredeweg and Forbus (2003), qualitative modeling is a valuable technology because much of education is concerned with conceptual knowledge (e.g., causal theories of physical phenomena). Environments using qualitative models may use diagrammatic representations to facilitate understanding of important concepts and relationships. Evaluations in educational settings provide support for the hypothesis that qualitative modeling tools can be valuable aids for learning (Frederiksen \& White, 2002; Leelawong et al., 2001).

\section{Cognitive Modeling}

Cognitive models may be quantitative or qualitative. They help predict complex human behaviors, including skill learning, problem solving, and other types of cognitive activities. Generally, cognitive models may apply across various domains, serve different functions, and model well- or ill-defined knowledge (e.g., design problems). The range of cognitive modeling approaches includes, for example, symbolic, connectionist, hybrid, neural, probabilistic, and deterministic mathematical models. Probably the best known examples of cognitive models come from the cognitive tutoring research by John Anderson and colleagues (Anderson, 1993; Anderson \& Lebiere, 1998; Anderson et al., 1990, 1995; Koedinger \& Anderson, 1998; Koedinger et al., 1997; Matsuda et al., 2005).

\section{Machine Learning}

Machine learning methods applicable for learner modeling include rule/tree (analogy) learning methods, probabilistic learning methods, and instance or case based learning approaches. A learner model can take advantage of machine learning methods and thus increase accuracy, efficiency, and extensibility in areas not modeled before (Sison \& Shimura, 1998). According to Webb and colleagues (2001), machine learning methods can be used to model: (1) cognitive processes underlying the learner's actions, (2) differences between the learner's skills and expert skills, (3) the learner's behavioral patterns or preferences, and (4) other characteristics of the learner. 


\section{Bayesian Networks}

Bayesian Networks are graphs composed of nodes and directional arrows (Pearl, 1988). Nodes represent variables and directed edges (arrows) between pairs of nodes indicate probabilistic relationships between variables (Pearl, 1988). Bayesian networks are related to the machine learning methods (see above) and are used within learner models to handle uncertainty by using probabilistic inference to update and improve belief values (e.g., regarding learner proficiencies). The inductive and deductive reasoning capabilities of Bayesian nets support "what if" scenarios by activating and observing evidence that describes a particular case or situation and then propagating that information through the network using the internal probability distributions that govern the behavior of the Bayesian net. Resulting probabilities inform decision making, as needed in, for example, our select process. Examples of Bayesian net implementations for LMs may be found in Conati et al. (2002), Shute, Hansen, and Almond (2008), and VanLehn and colleagues (2005).

\section{Stereotype Methods}

A stereotype is a collection of frequently occurring characteristics of users (e.g., physical characteristics, social background, computer experience). Adaptive methods are used to initially assign users to specific classes (stereotypes) so previously unknown characteristics can be inferred on the basis of the assumption that they will share characteristics with others in the same class (Kobsa, 2006). Creating stereotypes is a common approach to user modeling, whereby a small amount of initial information is used to assume a large number of default assumptions. When more information about individuals becomes available, the default assumptions may be altered (Rich, 1979). The two types of stereotyping are fixed and default. In fixed stereotyping, learners are classified according to their performance into a predefined stereotype that is determined by, for example, an academic level. Default stereotyping is a more flexible approach. At the beginning of a session, learners are stereotyped to default values, but, as the learning process proceeds and learner performance data is obtained, the settings of the initial stereotype are gradually replaced by more individualized settings (Kay, 2000).

\section{Overlay Methods}

An overlay model is a novice-expert difference model representing missing conceptions, often implemented as either an expert model annotated for missing items or an expert model with weights assigned to each element in the expert knowledge. The weights represent the probability of a student knowing a particular concept or having a misconception. One of the first uses of an 
overlay model was done with the WUSOR program (Stansfield et al., 1976). More recent applications of this overlay approach can be found in a variety of research projects (e.g., Kay, 1999; Vassileva, 1998; Zapata-Rivera \& Greer, 2000).

\section{Plan Recognition}

A plan is a sequence of actions (which may include choice points) to achieve a certain goal thus reflecting the learner's intentions and desires. Plan recognition is based on observing the learner's input actions and the system, and then inferring all possible learner plans based on the observed actions. According to Kobsa (1993), two main techniques are used to recognize the learner's plan: (1) establishing a plan library containing all possible plans where the selection of the actual plan is based on the match between observed actions and a set of actions in the library, and (2) plan construction where the system controls a library of all possible learner actions combined with the effects and the preconditions of these actions. Possible next actions may be calculated by comparing the effects of preceding actions with the preconditions of actions stored in the actions library. To read more about applying plan-recognition techniques in relation to instructional planning efforts, see Kobsa (1993) and Vassileva and Wasson (1992).

\section{Cumulative/Persistent Student Model}

The cumulative student model represents the more traditional approach where the LM is analyzed and updated in response to the learner's activities. This involves building a student model that captures and represents emerging knowledge, skills, and other attributes of the learner, with the computer responding to updated observations with modified content that can be minutely adjusted. The selection and presentation of subsequent content is dependent on individual response histories (Shute \& Psotka, 1996; VanLehn et al., 2005; Wenger, 1987). Student models can last for a long time and provide valuable information for various applications that keep track of long term goals and interests. Some researchers have explored these ideas in the context of lifelong user models (e.g., Kay \& Kummerfeld, this volume).

\section{Temporary Student Model}

Temporary student models usually do not persist in the system after the learner has logged out. In artificial intelligence, formalisms used to describe the world often face something called the frame problem which is the problem of inferring whether something that was true is still true; for example, the accuracy of cumulative (or persistent) student models can degrade as students forget 
things. Brooks (1999) and others have circumvented the frame problem by using the world as its own model (i.e., if you want to know if a window is closed, check the actual window rather than consult an internal model). The same idea applies to student modeling; that is, if you want to know if a student can still multiply two fractions, ask the student to multiply two fractions. This kind of student model is always up to date and corresponds to the short memory cycle scenario shown in Table 1.

\section{Pedagogical Agents}

Pedagogical means that these programs are designed to teach, and agent suggests that the programs are semiautonomous, possessing their own goals and making decisions on what actions to take to achieve their goals (i.e., a programmer has not predefined every action for them). The current generation of pedagogical agents is interactive and sometimes animated; for example, students can speak to agents that can speak back, often have faces and bodies, use gestures, and can move around a computer screen. Some well known agents include Steve (Johnson et al., 2000), AutoTutor (Graesser et al., 2001), AdeLE (Shaw et al., 1999), and the Tactical Language Training System (Johnson et al., 2004). An interesting application of agent technologies is teachable agents, which have been successfully used to promote student learning of mathematics and science (Biswas et al., 2001). This computer-based environment involves a multi-agent system (Betty's Brain) that implements a learning-by-teaching paradigm. Students teach Betty by using concept map representations with a visual interface. Betty is intelligent, not because she learns on her own but because she can apply qualitative-reasoning techniques to answer questions that are directly related to what she has been taught. Another class of agents is emotional agents (affective computing), which have been employed to support student learning (Picard, 1997; Wright, 1997). Getting students motivated and sustaining their motivation have historically been major obstacles in education. Emotional (or affective) agents create a learning environment involving learners and interactive characters (or believable agents). Two important aspects of such characters are that they appear emotional and can engage in social interactions. This requires a broad agent architecture and some degree of modeling of other agents in the environment. Finally, pedagogical or virtual agents can collaborate with students, enabling new types of interactions and support for learning (Johnson et al., 2000). 


\section{Hard Technologies}

In this section, we review several hardware-based technologies. These are mainly used for input (i.e., data capture) and output (presentation).

\section{Biologically Based Devices}

So-called biologically based devices obtain physical measures of the student's body or physical activity. They were originally developed to support learners with disabilities (i.e., assistive technologies); however, many are being created or repurposed to support learner models for both cognitive and noncognitive student data. As an example, obtaining information about where on the computer the learner is looking during learning provides evidence about the learner's current state and attentiveness (for good reviews of eye-tracking research, see Conati et al., 2005; Merten and Conati, 2006). This information can inform the system about what is the next optimal path to take for this particular learner. In terms of eye-tracking technology, eye movements, scanning patterns, and pupil diameter are indicators of thought and mental processing which occurs during learning from visual sources (Rayner, 1998); consequently, eye-tracking data can be used as the basis for supporting and guiding learners during the learning process. To illustrate the approach, consider a novel application of this technology known as AdeLE (García-Barrios et al., 2004). This introduces a realtime, eye-tracking procedure for intelligent user profile deduction as well as the use of a dynamic background library to support learning.

\section{Speech-Capture Devices}

These devices allow users to interact with the computer via speech, instead of relying on typing their input; consequently, this approach is valuable for individuals with physical disabilities that preclude typing, for young children who cannot yet type, and so on. The devices can also analyze speech profiles, and obtain information on other aspects of the person, such as stress. One example project using speech-capture technology is Project LISTEN (Literacy Innovation that Speech Technology ENables), by Jack Mostow and colleagues. This is an automated reading tutor that displays stories on a computer screen and listens to children read aloud. It intervenes when the reader makes mistakes, gets stuck, clicks for help, or is likely to encounter difficulty (Project LISTEN, 2006). See also D'Mello and Greasser, Chapter X, this volume, also Litman Chapter X, this volume. 


\section{Head-Gesture Capture Devices}

Many computers are currently equipped with video cameras. Processing the image provides a means to track head position and movement. Software by Visionics Corp., for example, provides this capability. Zelinsky and Heinzmann (1996) developed a system that can recognize 13 different head and face gestures. In addition, researchers in areas such as animated pedagogical and conversational agents have used sensors and a video camera for recognizing facial gestures (e.g., Kanade, Cohn, \& Tian, 2000). This information is used to facilitate human-agent interaction (Cassell et al., 2001).

\section{Assistive Technologies}

Disabilities and non-native language status can be major obstacles to learning from a computer. Examining adaptations in light of a validity framework can be valuable if not essential for ensuring effectiveness (for more on this topic, see Hansen \& Mislevy, 2005; Hansen et al., 2005). Currently, a growing number of sites on the web provide information for persons with special needs. See the Special Needs Opportunity Window (SNOW, 2006) web site for information about the different kinds of adaptive technologies for people with disabilities.

\section{Adaptive Environments}

When technologies (soft and hard) are integrated into a single environment or platform to accomplish the goal of enhancing student learning via adaptation, this is called an adaptive environment. We now examine several well-known types of adaptive environments.

\section{Adaptive Hypermedia Environment}

Adaptive hypermedia environments or systems (AHSs) are extended from an intelligent tutoring system foundation and combine adaptive instructional systems and hypermedia-based systems (Brusilovsky, 1996; Chapter X, this volume). An AHS combines hypertext and hypermedia, utilizes features of the learner in the model, and applies the LM during adaptation of visible aspects of the system to the learner. Brusilovsky (2001) distinguished between two different types of AHS: (1) adapting the presentation of content (i.e., different media formats or orderings), and (2) adapting the navigation or learning path, via direct guidance; hiding, reordering, or annotating links; or even disabling or removing links (Kinshuk \& Lin, 2004). 


\section{Adaptive Educational Hypermedia Environment}

A particular type of AHS is an adaptive educational hypermedia system (AEHS). The hyperspace of AEHS is kept relatively small given its focus on a specific topic; consequently, the focus of the LM is entirely on the domain knowledge of the learner (Brusilovsky, 1996). Henze and Nejdl (2003) have described AEHS as consisting of a document space, a learner model, observations, and an adaptation component which recommends content and changes the appearance of links and icons. The document space belongs to the hypermedia system and is enriched with associated information (e.g., annotations, domain or knowledge graphs). The LM stores, describes, and infers information, knowledge, and preferences about a learner. Observations represent the information about the interaction between the learner and the AEHS and are used for updating the LM.

\section{Collaborative Learning Environment}

An alternative approach to individualized learning is collaborative learning - that is, the notion that students, working together, can learn more than by themselves, especially when they bring complementary, rather than identical, contributions to the joint enterprise (Cumming and Self, 1989). Collaboration is a process by which "individuals negotiate and share meanings relevant to the problem-solving task at hand" (Teasley and Roschelle, 1993, p. 229). Research in this area examines methods to accurately capture and analyze student interactions in collaborative or distance learning environments; for example, Soller (2004) described various techniques (e.g., probabilistic machine learning) for modeling knowledge sharing interactions among different learners.

\section{Simulation and Immersive Environment}

Although simulations and immersive environments (e.g., virtual reality) change in response to specific user actions, typically the change is not due to an underlying LM but rather is a function of a predefined set of rules. Some simulations and immersive environments, however, do maintain a learner model (Rickel \& Johnson, 1997). Smithtown (Shute \& Glaser, 1990; Shute et al., 1989) is a simulated environment where students change parameters in the hypothetical town - such as percapita income, population, the price of gasoline - and see immediate changes in various markets, thus learning the laws of supply and demand. Smithtown actually maintains two learner models: one to model students' microeconomic knowledge and skills and the other to model their scientific inquiry skills. 
As we have just shown, many different programs and devices are available to capture, analyze, select, or present information to a learner based on current or perceived needs or wants. We now turn our attention to what some experts in the field have to say about adaptive technologies. Our goal is to provide additional perspectives on relevant topics.

\section{EXPERTS' THOUGHTS ON ADAPTIVE TECHNOLOGIES}

To supplement our literature review on adaptive technologies, we asked leading adaptivetechnology experts to address two questions: (1) what to adapt (i.e., what variables should be taken into account when implementing an adaptive system?), and (2) how to adapt (i.e., what are the best technologies and methods that you use or recommend?). The experts who responded to our e-mail queries include Cristina Conati, Jim Greer, Tanja Mitrovic, Julita Vassileva, and Beverly Woolf.

\section{What To Adapt?}

Our experts responded to the what-to-adapt question in two ways: (1) input data or learner variables to be measured and used as the basis for adaptation, and (2) output or instructional variables that adapt to learners' needs and occasionally to preferences. Table 2 summarizes their collective responses and illustrates a wide range of student variables and adaptive pedagogical responses.

Table 2. What to Adapt

\begin{tabular}{|l|l|}
\hline \multicolumn{1}{|c|}{ Variables } & \multicolumn{1}{c|}{ Examples } \\
\hline Learner Variables & \\
\hline Cognitive abilities & $\begin{array}{l}\text { Math skills, reading skills, cognitive development stage, problem solving, } \\
\text { analogical reasoning. }\end{array}$ \\
\hline Metacognitive skills & Self-explanation, self-assessment, reflection, planning. \\
\hline Affective states & Motivated, attentive, engaged, frustrated. \\
\hline Additional variables & Personality traits, learner styles, social skills, perceptual skills. \\
\hline $\begin{array}{l}\text { Instructional } \\
\text { Variables }\end{array}$ & \\
\hline Feedback & Types: hints, explanations; Timing: immediate, delayed. \\
\hline Content sequencing & Concepts, learning objects, tasks, items, cases or problems to solve. \\
\hline Scaffolding & Support and fading as warranted; rewards. \\
\hline View of material & $\begin{array}{l}\text { Overview, preview, review, as well as visualization of goal and/or solution } \\
\text { structure. }\end{array}$ \\
\hline
\end{tabular}




\section{How To Adapt?}

Responses to this question tended to focus on domain independent approaches and technologies based on analysis of student and pedagogical models. Table 3 lists the methods suggested by our experts which represent innovative implementations of the adaptive technologies discussed above.

Table 3. How to Adapt

\begin{tabular}{|c|c|}
\hline Adaptive Approach & Rationale \\
\hline Probability and decision theory & $\begin{array}{l}\text { Rule based approaches are typically used in adaptive systems, but using } \\
\text { probabilistic learner models provides formal theories of decision making for } \\
\text { adaptation. Decision theory takes into account the uncertainty in both model } \\
\text { assessment and adaptation actions' outcome, and combines it with a formal } \\
\text { representation of system objectives to identify optimal actions. (Conati, } \\
2006 \text { ) }\end{array}$ \\
\hline Constraint-based tutoring & $\begin{array}{l}\text { The domain model is represented as a set of constraints on correct solutions, } \\
\text { the long-term student model contains constraint histories, and these can be } \\
\text { used to generate the system's estimate of students' knowledge. Constraint } \\
\text { histories can also be used to generate a population student model (e.g., } \\
\text { probabilistic model), which can later be adapted with the student's data to } \\
\text { provide adaptive actions (e.g., problem or feedback selection). (Mitrovic, } \\
\text { 2006) }\end{array}$ \\
\hline Concept mapping & $\begin{array}{l}\text { In order to adapt content (e.g., sequences of concepts, learning objects, } \\
\text { hints) to the student, employ a concept map with prerequisite relationships, } \\
\text { an overlay model of the students' knowledge, and a reactive planning } \\
\text { algorithm. (Vassileva, 2006) }\end{array}$ \\
\hline Unsupervised machine learning & $\begin{array}{l}\text { Most existing student models are built by relying on expert knowledge, } \\
\text { either for direct model definition or for labeling data to be used by } \\
\text { supervised machine learning techniques. But relying on expert knowledge } \\
\text { can be very costly and for some innovative applications it may be even } \\
\text { impossible because the necessary knowledge does not exist. An alternative } \\
\text { is to use unsupervised machine learning to build student models from } \\
\text { unlabeled data using clustering techniques for defining classes of user } \\
\text { behaviors during learning environment interactions. (Conati, 2006) }\end{array}$ \\
\hline Exploiting learning standards & $\begin{array}{l}\text { Adapting around standardized content packages can make use (and reuse) } \\
\text { of large quantities of high quality content. This can be done by extending } \\
\text { the Shareable Content Object Reference Model (SCORM) Runtime } \\
\text { Environment specification to include user-modeling functionality. This } \\
\text { permits content authors to take advantage of (and update) LMs in a content } \\
\text { management system. Content recommendations to students are based on the } \\
\text { LM and recommendation is done in a light-weight manner with minimal } \\
\text { demands on content developers. (Greer \& Brooks, 2006) }\end{array}$ \\
\hline Analyzing expert teachers & $\begin{array}{l}\text { Studying expert teachers/tutors is an invaluable source of information on } \\
\text { how to adapt instructional content, but it is not always possible. Moreover, } \\
\text { for some innovative systems (e.g. educational games) human tutors may not } \\
\text { know how to provide effective pedagogical support. An alternative is to run }\end{array}$ \\
\hline
\end{tabular}




\begin{tabular}{|l|l|}
\hline & $\begin{array}{l}\text { So-called “Wizard of Oz" studies to test adaptation strategies defined via } \\
\text { pedagogical and/or cognitive theories and/or through intuition. (Conati, } \\
\text { 2006) }\end{array}$ \\
\hline $\begin{array}{l}\text { Matching instructional support to } \\
\text { cognitive ability }\end{array}$ & $\begin{array}{l}\text { Adapting instructional support to match students' cognitive needs (i.e., } \\
\text { developmental stage and different abilities) has been shown to promote } \\
\text { better learning in a couple of experimental studies (e.g., Arroyo, Woolf, \& } \\
\text { Beal, 2006; Arroyo, Beal, Murray, Walles, \& Woolf, 2004). The rationale is } \\
\text { that if students receive instructional support that they're not cognitively } \\
\text { ready to use, it will be less effective in promoting learning. (Woolf, 2006) }\end{array}$ \\
\hline
\end{tabular}

In this section, we have presented a variety of learner traits and states that are judged relevant to modeling in educational contexts. In addition to these variables to be captured and analyzed in the learner model, new data-mining technologies permit the discovery of even more learning variables for a more refined just-in-time collection of student information (for more, see Baker \& Yacef, 2009; Beck \& Woolf, 2000). This will allow systems to discover new things about a learner based on multiple sources of information from a single learner as well as from different learners. This sets the stage for accomplishing more accurate individual, as well as distributed and collaborative learner modeling in the future. Challenges and envisioned futures are discussed next.

\section{CHALLENGES AND FUTURE OF ADAPTIVE TECHNOLOGIES}

Several major obstacles must be overcome for the area of adaptive technologies to move forward. As in the previous section, we have augmented this section by directly asking leading researchers in the field of adaptive technologies to summarize their views on challenges and the future of adaptive technologies. Our experts include Anthony Jameson, Judy Kay, and Gord McCalla.

\section{Practical and Technical Challenges}

The main barriers to moving ahead in the area of adaptive educational technologies are obtaining useful and accurate learner information on which to base adaptive decisions, maximizing benefits to learners while minimizing costs associated with adaptive technologies, addressing issues relating to learner control and privacy, and figuring out the bandwidth problem, relating to the scope of learner data. Each of these is now described.

\section{Developing Useful Learner Models}

A core challenge of developing effective adaptive technologies is building useful LMs. According to Judy Kay (Kay, 2006), collecting meaningful learning traces (i.e., data obtained from records 
and student log files) should help overcome this challenge; that is, the large and increasing volume of learning trace data associated with individuals is generally trapped within logs of individual tools. As a consequence, these data represent a wasted, untapped resource that might be used to build rich LMs. To transform learning trace data into a LM, a process must interpret the data to infer relevant learner attributes, such as knowledge and preferences. This would require the addition of a knowledge layer that maps learner trace data (evidence) to a set of inferences about the learner's knowledge.

\section{Acquiring Valid Learner Data}

A related barrier to overcome involves the acquisition of valid learner data, particularly when accomplished via self reports (Kay, 2006). Self-report information has at least two problems. First, learners may enter inaccurate data either purposefully (e.g., based on concerns about privacy or a desire to present themselves in a flattering light) or by accident (e.g., lack of knowledge about the characteristics they are providing). This problem may be solved by maintaining separate views of the LM (e.g., the learner's view) and providing mechanisms for reconciling different views into one LM. Second, when additional interactions are required during the learning process (e.g., completing online questionnaires), this increases the time imposition and can lead to frustration (Kay, 2006) as well as potentially invalid data from students simply trying to get to the content quickly (Greer \& Brooks, 2006). Gathering such information, however, can not only reduce the complexity of diagnosis but also encourage students to become more active participants in learning and assume greater responsibility for their own LMs.

\section{Maximizing Benefits}

Currently, the cost of developing and employing adaptive technologies is often quite high while the return on investment is equivocal. This challenge is a practical one-how to maximize the benefitto-cost ratio of adaptive technologies. Despite a growing number of adaptive technologies available today, there are too few controlled evaluations of the technologies and systems.

According to Jameson (2006), addressing this problem should begin with the identification of specific conditions that warrant adaptation. There are at least two standards of comparison for adaptivity: (1) fixed sequencing, and (2) learner control of content. The question is whether these comparison conditions accomplish the same goals that could be achieved via adaptation. Jameson (2006) offers a strategy for finding appropriate adaptivity applications-look for cases where the learner is in a poor position to select content herself, such as: (1) the learner wants to choose an 
item from a very large set of items whose properties the learner is not familiar with, and (2) the learner is in a situation lacking in the resources that would be required for effective performance.

\section{Minimizing Costs}

One straightforward way to minimize the technical costs associated with adaptivity involves the use of more or less off-the-shelf technology for user adaptivity (Fink \& Kobsa, 2000; Jameson, 2006). Another cost-minimizing option has been suggested by Greer and Brooks (2006) that involves leveraging existing content. They note that adaptive algorithms are often domain specific, requiring the hand coding of content to fit the specific form of adaptation. But, with the growing use of standardized content management systems and content available with descriptive metadata, the adaptive learning community has the opportunity to get in on the ground floor in creating standards for content adaptation (see Flynn, Chapter $\mathrm{X}$ this volume) Their approach involves creating formal ontologies to capture content, context, and learning outcomes. Instances of these ontologies can be reasoned over by a learning environment to provide content (and peer help) recommendations. Formal ontologies may then be shared (e.g., via Semantic Web specifications) and provide a clear set of deduction rules as well as extensive tool support.

\section{Dealing with Learner Control Issues}

Learners often want to control their learning environment. One strategy that addresses this desire is to allow them partial control of the process. According to Jameson (2006), there are several ways to divide the job of making a learning-path decision by the system vs. the learner (see Wickens \& Hollands, 2000, chap. 13). The system can (1) recommend several possibilities and allow the learner to choose from that list; (2) ask the learner for approval of a suggested action; or (3) proceed with a particular action but allow the learner to interrupt its execution of the action.

\section{Addressing Privacy and Obtrusiveness Concerns}

When a system has control of the learning environment and automatically adapts, its behavior may be viewed by learners as relatively unpredictable, incomprehensible, or uncontrollable (Jameson, 2008). Moreover, the actions that the system performs to acquire information about the learner or to obtain confirmation for proposed actions may make the system seem obtrusive or threaten the learner's privacy (Kobsa, 2002). According to Kay (2006), one way to address this concern is to build all parts of the learner modeling system in a transparent manner to ensure that the learner can 
scrutinize the system's management of their data and the way in which those data are interpreted (Cook \& Kay, 1994).

\section{Considering the Scope of the Learner Model}

According to McCalla (2006), adapting to individual differences is essential to making adaptive systems more effective. Despite some support for this claim (Arroyo et al., 2004, 2006), significantly more experimental studies are needed. The traditional approach to achieving adaptivity has required the system to maintain a LM that captures certain characteristics of each learner and then use those data as the basis for adapting content (Greer \& McCalla, 1994). One major problem concerns obtaining sufficient bandwidth of learner interactions to allow the capture of a sufficient range of characteristics to paint an accurate picture of the learner for appropriate adaptation. Bandwidth in this case refers to the amount of relevant learner data that can be passed along a communications channel in a given period of time. The bad news is that it is difficult to maintain a consistent model as learners' knowledge and motivations change over time; but the good news is that the bandwidth problem is diminishing as learners are currently spending more time interacting with technology (McCalla, 2006), and it is possible to gather a broad range of information about them. Moreover, learners' interactions can now be recorded at a fine enough grain size to produce more depth in the LM. The maintenance problem may be addressed by the simple expedient of not trying to maintain a persistent LM but instead making sense of a learner's interactions with an adaptive system just in time to achieve particular pedagogical goals.

Having summarized the main challenges surrounding adaptive technologies and possible ways to overcome them, we now present some visions of where the field may be heading in the future. These views have been crafted from the answers provided by three experts to our questions.

\section{The Future of Adaptive Technology}

\section{Judy Kay's Views}

A long-term vision for adaptive technologies involves the design and development of life-long learner models under the control of each learner. This idea draws on the range of learning traces available from various tools and contexts. Learners could release relevant parts of their life-long LMs to new learning environments. Realizing such a vision requires that all aspects of the LM and its use are amenable to learner control. Part of the future for LMs of this type must include the aggregation of information across models. This relates back to two major challenges: privacy and 
user control of personal data, as well as its use and reuse. An important part of addressing these issues will be to build LMs and associated applications so learners can always access and control their LMs and their use. This approach must go beyond just making the LM more open and inspectable to ensuring that learners actually take control of its use.

\section{Gord McCalla's Views}

The next envisioned future of adaptive technologies relates to the ecological approach. The learning environment is assumed to be a repository of known learning objects, but both learning object and repository are defined broadly to include a variety of learning environments. To further enhance flexibility, the repository may also include: (1) artificial agents representing learning objects, and (2) personal agents representing users (e.g., learners, tutors, and teachers). In this vision, each agent maintains models of other agents and users that help the agent achieve its goals. The models contain raw data tracked during interactions between the agents and users (and other agents), as well as inferences drawn from the raw data. Such inferences are only made as needed (and as resources allow) while an agent is trying to achieve a pedagogical goal. This is called active modeling (McCalla et al., 2000). After a learner has interacted with a learning object, a copy of the model that her personal agent has been keeping can be attached to the learning object. This copy is called a learner model instance and represents the agent's view of the learner during this particular interaction, both what the personal agent inferred about the learner's characteristics and how the learner interacted with the system. Over time, each learning object slowly accumulates LM instances that collectively form a record of the experiences of many different learners as they have interacted with the learning object. To achieve various pedagogical goals, agents can mine LM instances - attached to one or more learning objects - for patterns about how learners interacted with the learning objects. The approach is called ecological because the agents and objects in the environment must continuously accumulate information, and there can be natural selection as to which objects are useful or not. Useless objects and agents can thus be pruned. Moreover, ecological niches may exist that are based on goals (e.g., certain agents and learning objects are useful for a given goal while others are not). Finally, the whole environment evolves and changes naturally through interaction among the agents and ongoing attachment of LM instances to learning

objects. The ecological approach will require research into many issues (e.g., experimentation to discover algorithms that work for particular kinds of pedagogical goals). 


\section{Anthony Jameson's Views}

Although there are many improvements that can and should be made in terms of tools and techniques for adaptation, it is even more important to focus on the central problem of getting the benefits to exceed the costs. Adaptivity, like many other novel technologies, is a technology that is worthwhile, albeit within a restricted range of settings. It is thus critically important to clearly identify these settings and to solve the adaptation problems therein. The ultimate goal is to enhance (in the short or middle term) the usability and effectiveness of real systems in the real world.

\section{SUMMARY AND DISCUSSION}

Adaptive systems have been, and will continue to evolve as new technologies appear in the field and old ones transform and become more established. The future of the field is wide open in that it can evolve in different ways depending on factors such as the emergence of new technologies, new media, advances in learning, measurement, and artificial intelligence, and general policies and standards that take hold (or not) in relation to adaptive instruction and learning. One shift that we see as critically important to the field, particularly in the near term, is toward conducting controlled evaluations of adaptive technologies and systems. This will enable the community to gauge the value-added of these often expensive technologies in relation to improving student learning or other valued proficiencies (e.g., self esteem, motivation). Our review has shed light on a range of technologies, but the bottom line has not yet been addressed: What works, for whom, and under which conditions and contexts? Conati (2006) asserts and we agree that learners' traits targeted for adaptation should clearly improve the pedagogical effectiveness of the system. This depends on whether or not: (1) a given trait is relevant to achieve the system's pedagogical goals; (2) there is enough learner variability on the trait to justify the need for individualized interaction; and (3) there is sufficient knowledge on how to adapt to learner differences along this trait. Along the same lines, Jameson (2006) argues that the benefits of adaptation should be weighed against the cost of modeling each candidate trait, to focus on traits that provide the highest benefit given the available resources.

A similar appeal for conducting controlled evaluations was made more than a decade ago, during the heyday of intelligent tutoring system development. Now, as then, the call for evaluations of adaptive technologies and systems is crucial for future development efforts to succeed in terms of promoting learning. Building adaptive systems and not evaluating them is like "building a boat and 
not taking it in the water" (Shute \& Regian, 1993, p. 268). Evaluation is not only important to the future of the field but can also be as exciting as the process of developing the tools and systems. And, although the results may be surprising or humbling, they will always be informative.

\section{ACKNOWLEDGMENTS}

We would like to acknowledge the experts cited herein who provided us with thoughtful and insightful responses to our adaptive technology queries: Chris Brooks, Cristina Conati, Jim Greer, Anthony Jameson, Judy Kay, Gord McCalla, Tanja Mitrovic, Julita Vassileva, and Beverly Woolf. We'd also like to thank Paula Durlach and Alan Lesgold for their very sage comments on an earlier draft of this chapter.

\section{References}

Alexander, P. A., \& Judy, J. E. (1988). The interaction of domain-specific and strategic knowledge in academic performance. Review of Educational Research, 58(4), 375-404.

Anderson, J. R. (1993). The Adaptive Character of Thought. Hillsdale, NJ: Lawrence Erlbaum.

Anderson, J. R., \& Lebiere, C. (1998). The atomic components of thought. Mahwah, NJ: Lawrence Erlbaum.

Anderson, J. R., Boyle, C. F., Corbett, A. T., \& Lewis, M. (1990). Cognitive modeling and intelligent tutoring, Artificial Intelligence, 42, 7-49.

Anderson, J. R, Corbett, A. T., Koedinger, K. R., \& Pelletier, R. (1995). Cognitive tutors: Lessons learned. Journal of the Learning Sciences, 4, 167-207.

Arroyo, I., Woolf, B. P., \& Beal, C. R. (2006). Addressing cognitive differences and gender during problem solving, Technology, Instruction, Cognition \& Learning, 3(1), 31-63.

Arroyo, I., Beal, C. R., Murray, T., Walles, R. \& Woolf, B. P. (2004). Web-based intelligent multimedia tutoring for high stakes achievement tests. Intelligent Tutoring Systems, 7th International Conference, ITS 2004, Maceiò, Alagoas, Brazil, Proceedings. Lecture Notes in Computer Science 3220 (pp. 468-477). Berlin: Springer Verlag. 
Azambuja Silveira, R. \& Vicari, R. M. (2002). Developing distributed intelligent learning environment with JADE - Java Agents for Distance Education Framework. Intelligent Tutoring Systems, 2363, 105-118.

Baker, R. S., \& Yacef, K. (2009). The state of educational data mining in 2009: A review and future visions. Journal of Educational Data Mining, 1, 3-17.

Beck, J., \& Woolf, B. (2000). High-level student modeling with machine learning. Proceedings of the 5th International Conference on Intelligent Tutoring Systems, 584-593.

Biswas, G., Schwartz, D., Bransford, J., and the Teachable Agent Group at Vanderbilt (TAG-V) (2001). Technology support for complex problem solving: From SAD environments to AI. In K. D. Forbus and P. J. Feltovich (Eds.), Smart machines in education: The coming revolution in educational technology (pp. 71-97). Menlo Park, CA: AAAI/MIT Press.

Bredeweg, B. \& Forbus, K. (2003). Qualitative Modeling in Education. AI Magazine, 24(4), 35-46.

Bretzke H., \& Vassileva J. (2003) Motivating cooperation in peer-to-peer networks. Proceedings from the User Modeling UM03 Conference, (pp. 218-227). Berlin: Springer Verlag.

Brooks, R. A. (1999). Cambrian intelligence: The early history of the new AI. Cambridge, MA: MIT Press.

Brusilovsky, P. (1996). Methods and techniques of adaptive hypermedia. User Modeling and User Adapted Interaction, 6(2-3), 87-129.

Brusilovsky, P. (2001). Adaptive hypermedia. User Modeling and User-Adapted Interaction, $11(1 / 2), 87-110$.

Brusilovsky, P., Sosnovsky, S., \& Shcherbinina, O. (2005). User modeling in a distributed elearning architecture. In L. Ardissono, P. Brna, \& A. Mitrovic (Eds.), Proceedings of 10th International User Modeling Conference (pp. 387-391). Berlin: Springer Verlag.

Buxton, W. (2006). A directory of sources for input technologies. Retrieved October 3, 2006 from, http://www.billbuxton.com/InputSources.html

Cassell, J., Nakano, Y., Bickmore, T., Sidner, C., \& Rich, C. (2001). Annotating and generating posture from discourse structure in embodied conversational agents. Workshop on Representing, 
Annotating, and Evaluating Non-Verbal and Verbal Communicative Acts to Achieve Contextual Embodied Agents, Autonomous Agents, Conference, Montreal, Quebec.

Chu, C., \& Cohen, I. (2005). Posture and gesture recognition using 3D body shapes decomposition. IEEE Workshop on Vision for Human-Computer Interaction (V4HCI), Retrieved October 2, 2006 from, http://iris.usc.edu/ icohen/pdf/Wayne-v4hci05.pdf

Conati, C. (2002). Probabilistic assessment of user's emotions in educational games. Journal of Applied Artificial Intelligence, 16(7-8), 555-575.

Conati, C. (2006). What to Adapt, and How? Personal communication, May 18, 2006, 1-2.

Conati, C., Gertner, A., \& VanLehn, K. (2002). Using Bayesian networks to manage uncertainty in student modeling. Journal of User Modeling and User-Adapted Interaction, 12(4), 371-417.

Conati, C., Merten, C., Muldner, K., \& Ternes, D. (2005). Exploring eye-tracking to increase bandwidth in user modeling. In Proceedings of UM2005 User Modeling: Proceedings of the Tenth International Conference. Edinburgh, UK. Retrieved October 29, 2006 from, http://www.cs.ubc.ca/ conati/my-papers/um05-eyetracking-camera.pdf.

Conchas, G. (2006). The color of success: Race and high achieving urban youth. New York: Teachers College Press.

Cook, R., \& Kay, J. (1994). The justified user model: a viewable, explained user model. In A. Kobsa, \& D. Litman (Eds.), Proceedings of the Fourth International Conference on User Modeling UM94, (pp. 145-150), Hyannis, MA: MITRE, UM Inc.

Craig, S. D., Graesser, A. C., Sullins, J. \& Gholson, B. (2004). Affect and learning: An exploratory look into the role of affect in learning with AutoTutor. Journal of Educational Media, 29(3), 241-250.

Cumming, G., \& Self, J. (1989). Collaborative intelligent educational systems. In D. Bierman, J. Breuker \& J. Sandberg (Eds.), Proceedings of Artificial Intelligence and Education (pp. 73-80). Amsterdam: IOS.

Desimone, L. (1999). Linking parent involvement with student achievement: Do race and income matter. The Journal of Educational Research, 93(1), 11-30. 
Ekman, P. (2003). Emotions revealed: recognizing faces and feelings to improve communication and emotional life. New York: Henry Holt.

Fan, X., \& Chen, M. (2001). Parental involvement and students' academic achievement: A metaanalysis. Educational Psychology Review, 13(1), 1-22.

Fink, J., \& Kobsa, A. (2000). A review and analysis of commercial user modeling servers for personalization on the world wide web. User Modeling and User-Adapted Interaction, 10, 209249.

Frederiksen, J., \& White, B. (2002). Conceptualizing and constructing linked models: Creating coherence in complex knowledge systems. In P. Brna, M. Baker, K. Stenning, \& A. Tiberghien (Eds.), The role of communication in learning to model (pp. 69-96). Mahwah, NJ: Lawrence Erlbaum.

Fröschl, C. (2005). User modeling and user profiling in adaptive e-learning systems: An approach for a service-based personalization solution for the research project AdeLE (Adaptive eLearning with Eye-Tracking). Unpublished master's thesis, Graz University of Technology, Graz, Austria.

García-Barrios, V. M.; Gütl, C.; Preis, A.; Andrews, K.; Pivec, M.; Mödritscher, F.; Trummer, C. (2004). AdELE: A Framework for Adaptive E-Learning through Eye Tracking. In Proceedings of I-KNOW'04 (pp. 609-616), Graz, Austria, 2004.

Glaser, R. (1984). Education and thinking: The role of knowledge. American Psychologist, 39(2), 93-104.

González, G., Angulo, C., López, B. and de la Rosa, J. L. (2005). Smart user models: Modelling the humans in ambient recommender systems. In Proceedings of the Workshop on Decentralized, Agent Based and Social Approaches to User Modelling (DASUM 2005), pp. 1120.

Graesser, A. C., Person, N., Harter, D., \& TRG (2001). Teaching tactics and dialog in AutoTutor. International Journal of Artificial Intelligence in Education, 12, 257-279.

Greer, J., \& Brooks, C. (2006). What to Adapt, and How? Personal communication, May 16, 2006, $1-2$. 
Greer, J. E. \& McCalla, G. I. (1994) (Eds.), Student Modelling: The Key to Individualized Knowledge-Based Instruction, Berlin: Springer Verlag.

Hansen, E. G., \& Mislevy, R. J. (2005). Accessibility of computer-based testing for individuals with disabilities and English language learners within a validity framework. In M. Hricko \& S. Howell (Eds.), Online assessment and measurement: Foundation, challenges, and issues. Hershey, PA: Idea Group Publishing, Inc.

Hansen, E. G., Mislevy, R. J., Steinberg, L. S., Lee, M. J., \& Forer, D. C. (2005). Accessibility of tests for individuals with disabilities within a validity framework. System: An International Journal of Educational Technology and Applied Linguistics, 33(1), 107-133.

Henze, N., \& Nejdl, W. (2003). Logically characterizing adaptive educational hypermedia systems. In Proceedings of the AH 2003 - Workshop on Adaptive Hypermedia and Adaptive Web-Based Systems, Budapest, Hungary.

Jameson, A. (1995). Numerical uncertainty management in user and student modeling: An overview of systems and issues. User Modeling and User-Adapted Interaction, 5(3-4), 193-251

Jameson, A. (2006). Challenges and future of learner modeling. Personal communication, May 24, 2006, 1-4.

Jameson, A. (2008). Adaptive interfaces and agents. I n A. Sears \& J. A. Jacko (Eds.), The humancomputer interaction handbook: Fundamentals, evolving technologies and emerging applications (2nd ed.) (pp. 433-458). Mahwah, NJ: Lawrence Erlbaum.

Johnson, W. L, \& Rickel, J. (1997). Steve: An animated pedagogical agent for procedural training in virtual environments. ACM SIGART Bulletin, 8(1-4), 16-21.

Johnson, W. L.; Rickel, J. W.; and Lester, J. C. (2000). Animated Pedagogical Agents: Face-toFace Interaction in Interactive Learning Environments. International Journal of Artificial Intelligence in Education, 11(1), 47-78.

Johnson. W. L., Beal, C., Fowles-Winkler, A., Narayanan, S., Papachristou, D., Marsella, S., \& Vilhjálmsson, H. (2004). Tactical Language Training System: An interim report. Proceedings of Intelligent Tutoring Systems 2004 (ITS 2004). Berlin: Springer Verlag. 
Kabassi, K., \& Virvou, M. (2003). Using web services for personalised web-based learning. Educational Technology \& Society, 6(3), 61-71. Retrieved October 10, 2006 from, http://ifets.ieee.org/periodical/6 3/8.html.

Kanade, T., Cohn, J. F., \& Tian, Y. (2000). Comprehensive database for facial expression analysis. Proceedings of the Fourth IEEE International Conference on Automatic Face and Gesture Recognition ( $\left.F G^{\prime} 00\right)$, Grenoble, France, pp. 46-53.

Kapoor, A., \& Picard, R. W. (2002). Real-time, fully automatic upper facial feature tracking. Paper presented at the 5th International Conference on Automatic Face and Gesture Recognition, Washington, D.C.

Kay, J. (1999). A scrutable user modelling shell for user-adapted interaction. Ph.D. Thesis, Basser Department of Computer Science, University of Sydney, Sydney, Australia.

Kay, J. (2000). Stereotypes, student models and scrutability. In G. Gauthier, G., Frasson, C., \& K. VanLehn, (Eds.), Lecture Notes in Computer Science, (pp. 19-30), Berlin: Springer Verlag.

Kay, J. (2006). Challenges and future of learner modeling. Personal communication, June 6, 2006, $1-4$.

Kettebekov, S., Yeasin, M, \& Sharma, R. (2003). Improving continuous gesture recognition with wpoken prosody. In IEEE Computer Society Conference on Computer Vision and Pattern Recognition (CVPR), pp. 565-570.

Kinshuk \& Lin, T. (2004). Cognitive profiling towards formal adaptive technologies in Web-based learning communities. International Journal of WWW-based Communities, 1(1), 103-108.

Kobsa, A. 1993. User modeling: Recent work, prospects and hazards. In Adaptive User Interfaces: Principles and Practice (pp. 111-128). In T. K. M. Schneider-Hufschmidt and U. Malinowski (Eds.), North-Holland, Amsterdam, the Netherlands.

Kobsa, A. (2002). Personalization and international privacy. Communications of the ACM 45(5), 64-67.

Kobsa, A. (2006). Generic user modeling systems and servers. In P. Brusilovsky, A. Kobsa, \& W. Neijdl (Eds.), The adaptive web: Methods and strategies of web personalization. Berlin: Springer Verlag. 
Koedinger, K. R. \& Anderson, J. R. (1998). Illustrating principled design: The early evolution of a cognitive tutor for algebra symbolization. Interactive Learning Environments, 5, 161-180.

Koedinger, K. R., Anderson, J. R., Hadley, W. H., \& Mark, M. A. (1997). Intelligent tutoring goes to school in the big city. International Journal of Artificial Intelligence in Education, 8, 30-43.

Leelawong, K., Wang, Y., Biswas, G., Vye, N., \& Bransford, J. (2001). Qualitative reasoning techniques to support learning by teaching: The teachable agents project. In G. Biswas (Ed.), Proceedings of the Fifteenth International Workshop on Qualitative Reasoning, St. Mary's University, San Antonio, TX.

Litman, D. J. \& Forbes-Riley, K. (2004). Predicting student emotions in computer-human tutoring dialogues. Proceedings of the 42nd Annual Meeting of the Association for Computational Linguistics (ACL) (pp. 351-358). Barcelona, Spain.

Matsuda, N., Cohen, W. W., \& Koedinger, K. R. (2005). An intelligent authoring system with programming by demonstration. In Proceedings of the Japan National Conference on Information and Systems in Education. Kanazawa, Japan.

McCalla. G. I. (2004). The ecological approach to the design of e-learning environments: Purposebased capture and use of information about learners. In T. Anderson \& D. Whitelock (Guest Eds.), Journal of Interactive Media in Education, Special Issue on the Educational Semantic Web (pp. 1-23). Retrieved September 22, 2006 from, http://wwwjime.open.ac.uk/2004/7/mccalla-2004-7.pdf

McCalla, G. I. (2006). Challenges and future of learner modeling. Personal communication, May 26, 2006, 1-4.

McCalla, G. I., Vassileva, J., Greer, J. E., \& Bull, S. (2000). Active learner modeling. In G. Gauthier, C. Frasson, and K. VanLehn (Eds.) Proceedings of the International Conference on Intelligent Tutoring Systems (pp. 53-62.), Berlin: Springer Verlag.

Merten, C., \& Conati, C. (2006). Eye-tracking to model and adapt to user meta-cognition in Intelligent Learning Environments. Proceedings of International Conference on Intelligent User Interfaces (IUI 06), Syndey, Australia. Retrieved October 31, 2006 from, http://www.cs.ubc.ca/ conati/my-papers/IUI06eyetrackingCamera.pdf 
Mislevy, R. J., Steinberg, L. S., \& Almond, R. G. (2003). On the structure of educational assessments. Measurement: Interdisciplinary Research and Perspectives, 1(1), 3-62.

Mitrovic, A. (2006). What to Adapt, and How? Personal communication, May 17, 2006, 1-2.

Park, O. \& Lee, J. (2004). Adaptive instructional systems. In D. H. Jonassen (Ed.) Handbook of Research for Educational Communications and Technology, (pp. 651-685). Mahwah, NJ: Lawrence Erlbaum.

Pearl, J. (1988). Probabilistic reasoning in intelligent systems: Networks of plausible inference. San Mateo, CA: Kaufmann.

Picard, R.W. (1997). Affective computing. Cambridge, MA: MIT Press.

Potamianos, A., Narayanan, S., \& Riccardi, G. (2005). Adaptive categorical understanding for spoken dialogue systems, in IEEE Transactions on Speech and Audio Processing, Vol. 13, pp.321 - 329.

Project LISTEN (2006). Retrieved October 28, 2006 from, http://www.cs.cmu.edu/ listen/

Qu, L., Wang N., \& Johnson, W. L. (2005). Detecting the learner's motivational states in an interactive learning environment. In C.-K. Looi et al. (Eds.), Artificial Intelligence in Education (pp. 547-554), IOS Press.

Rayner, K. (1998). Eye movements in reading and information processing: 20 years of research. Psychological Bulletin, 124, 372-422.

Rich, E. (1979). User modeling via stereotypes. Cognitive Science, 3(4), 329-354.

Rickel, J., \& Johnson, W. L. (1997). Intelligent tutoring in virtual reality. In Proceedings of Eighth World Conference on AI in Education, pp. 294-301.

Seo, K., Cohen, I., You, S., \& Neumann, U. (2004). Face pose estimation system by combining hybrid ICA-SVM learning and re-registration. Asian Conference on Computer Vision (ACCV), Jeju, Korea.

Shaw, E., Johnson, W. L., \& Ganeshan, R. (1999). Pedagogical agents on the Web. In Proceedings of the Third International Conference on Autonomous Agents, pp. 283-290. 
Shute, V. J. (2007). Tensions, trends, tools, and technologies: Time for an educational sea change. In C. A. Dwyer (Ed.), The future of assessment: Shaping teaching and learning (pp. 139-187). New York, NY: Lawrence Erlbaum Associates, Taylor \& Francis Group.

Shute, V. J. \& Glaser, R. (1990). Large-scale evaluation of an intelligent tutoring system: Smithtown. Interactive Learning Environments, 1, 51-76.

Shute, V. J., \& Psotka, J. (1996). Intelligent tutoring systems: Past, present, and future. In D. Jonassen (Ed.), Handbook of Research for Educational Communications and Technology (pp. 570-600). New York, NY: Macmillan.

Shute, V. J. \& Regian, J. W. (1993) Principles for evaluating intelligent tutoring systems. Journal of Artificial Intelligence in Education, 4(3), 245-271.

Shute, V. J., Glaser, R. \& Raghavan, K. (1989). Inference and discovery in an exploratory laboratory. In P.L. Ackerman, R.J. Sternberg \& R. Glaser (Eds.), Learning and Individual Differences (pp. 279-326). New York: W.H. Freeman.

Shute, V. J., Graf, E. A., \& Hansen, E. (2005). Designing Adaptive, Diagnostic Math Assessments for Individuals With and Without Visual Disabilities. In L. PytlikZillig, R. Bruning, and M. Bodvarsson (Eds.). Technology-Based Education: Bringing Researchers and Practitioners Together (pp. 169-202). Greenwich, CT: Information Age Publishing.

Shute, V. J., Hansen, E. G., \& Almond, R. G. (2008). You can't fatten a hog by weighing it - Or can you? Evaluating an assessment for learning system called ACED. International Journal of Artificial Intelligence and Education, 18(4), 289-316.

Shute, V. J., Lajoie, S. P., \& Gluck, K. A. (2000). Individualized and group approaches to training. In S. Tobias \& J. D. Fletcher (Eds.), Training and Retraining: A Handbook for Business, Industry, Government, and the Military (pp. 171-207). New York: Macmillan.

Sison, R., \& Shimura, M. (1998). Student modeling and machine learning. International Journal of Artificial Intelligence in Education, 9, 128-158.

Snow, C. E., \& Biancarosa, G. (2003). Adolescent literacy and the achievement gap: What do we know and where do we go from here? New York: Carnegie Corporation of New York. 
Snow, R. E. (1989). Toward assessment of cognitive and conative structures in learning. Educational Researcher, 18(9), 8-14.

Snow, R. E. (1994). Abilities in academic tasks. In R. J. Sternberg \& R. K. Wagner (Eds.), Mind in context: Interactionist perspectives on human intelligence (pp. 3-37). New York: Cambridge University Press.

SNOW (2006). Retrieved October 28, 2006 from, http://snow.utoronto.ca/technology/

Soller, A. (2004). Computational modeling and analysis of knowledge sharing in collaborative distance learning, User Modeling and User-Adapted Interaction, 14(4), 351-381.

Stansfield, J., Carr, B., \& Goldstein, I. (1976). Wumpus advisor: A first implementation of a program that tutors logical and probabilistic reasoning skills. (Technical Report 381), MIT, Artificial Intelligence Laboratory, Cambridge, MA.

Teasley, S. D., \& Rochelle, J. (1993). Constructing a joint problem space: The computer as a tool for sharing knowledge. In S. P. Lajoie \& S. J. Derry (Eds.), Computers as cognitive tools (pp. 229-258). Hillsdale, NJ: Lawrence Erlbaum.

Tobias, S. (1994). Interest, prior knowledge, and learning. Review of Educational Research, 64(1), $37-54$.

Trella, M., Carmona, C., \& Conejo, R. (2005). MEDEA: An open service-based learning platform for developing intelligent educational systems for the Web. In Proceedings of Workshop on Adaptive Systems for Web based Education at 12th International Conference on Artificial Intelligence in Education (pp. 27-34), Amsterdam, IOS Press.

VanLehn, K., Lynch, C., Schulze, K., Shapiro, J. A., Shelby, R., Taylor, L., Treacy, D., Weinstein, A., \& Wintersgill, M. (2005). The Andes Physics Tutoring System: Lessons Learned. International Journal of Artificial Intelligence and Education, 15(3), 147-204.

Vassileva, J. (1998). DCG +GTE: Dynamic courseware generation with teaching expertise. Instructional Science, 26(3/4), 317-332.

Vassileva, J. (2006). What to Adapt, and How? Personal communication, May 15, 2006, 1-2. 
Vassileva, J. \& Wasson, B. (1996). Instructional planning approaches: from tutoring towards free learning. Proceedings of EuroAIED (pp. 1-8). Lisbon, Portugal.

Vassileva, J., McCalla, G. I., \& Greer, J. E., (2003). Multi-Agent Multi-User Modeling in I-Help. User Modeling and User-Adapted Interaction, 13 (1-2), 179-210.

Webb, G., Pazzani, M. J., Billsus, D. (2001). Machine learning for user modeling. User Modeling and User-Adapted Interaction, 11, 19-29.

Wenger, E. (1987). Artificial intelligence and tutoring systems. Los Altos: Morgan Kaufmann Publishers.

Wickens, C. D., \& Hollands, J. G. (2000). Engineering psychology and human performance (3 ${ }^{\text {rd }}$ Edition). Upper Saddle River, NJ: Prentice Hall.

Winter, M., Brooks, C., \& Greer, J. (2005) Towards best practices for semantic web student modelling. In the 12th International Conference on Artificial Intelligence in Education (AIED 2005), July $18-22,2005$.

Woolf, B. (2006). What to Adapt, and How? Personal communication, May 22, 2006, 1-2.

Wright, I. (1997). Emotional Agents. PhD thesis, University of Birmingham. Retrieved May 25, 2006 from, http://citeseer.ist.psu.edu/wright97emotional.html.

Yang, M., Zapata-Rivera, D., \& Bauer, M. (2006). E-Grammar: An assessment-based learning environment for English grammar. In Proceedings of the Annual Conference of Ed-Media. Orlando, FL.

Yeasin, M., \& Bullot, B. (2005). Comparison of linear and non-linear data projection techniques in recognizing universal facial expressions. In Proceedings of International Joint Conference on Neural Networks, Vol. 5, pp. 3087-3092.

Zapata-Rivera, D., \& Greer, J. (2000). Inspecting and visualizing distributed Bayesian student models. Proceedings of the 5th International Conference on Intelligent Tutoring Systems (pp. 544-553), Berlin: Springer Verlag.

Zapata-Rivera, D. \& Greer, J. (2004) Inspectable Bayesian student modelling servers in multiagent tutoring systems, International Journal of Human-Computer Studies, 61(4), 535-563. 
Zelinsky, A., \& Heinzmann, J. (1996). Real-time visual recognition of facial gestures for humancomputer interaction. Proceedings of the Second International Conference on Automatic Face and Gesture Recognition, Killington, VT. 